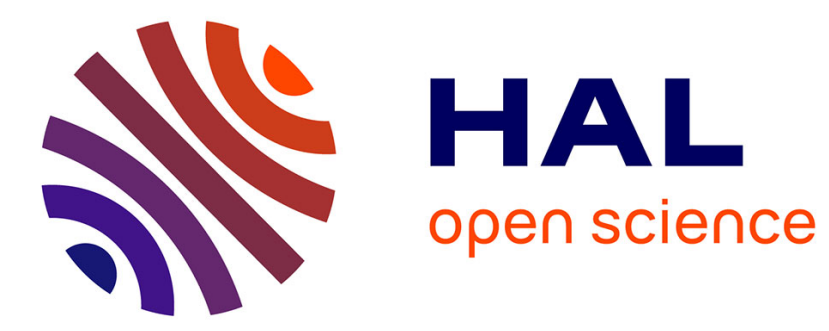

\title{
Positron Annihilation for the Non-Destructive Assessment of the Early Stages of Damage
}

\author{
M. Hutchings, D. Buttle, R. Colbrook, W. Dalzell, C. Scruby
}

\section{To cite this version:}

M. Hutchings, D. Buttle, R. Colbrook, W. Dalzell, C. Scruby. Positron Annihilation for the NonDestructive Assessment of the Early Stages of Damage. Journal de Physique IV Proceedings, 1995, 05 (C1), pp.C1-111-C1-117. 10.1051/jp4:1995112 . jpa-00253548

\section{HAL Id: jpa-00253548 https://hal.science/jpa-00253548}

Submitted on 1 Jan 1995

HAL is a multi-disciplinary open access archive for the deposit and dissemination of scientific research documents, whether they are published or not. The documents may come from teaching and research institutions in France or abroad, or from public or private research centers.
L'archive ouverte pluridisciplinaire HAL, est destinée au dépôt et à la diffusion de documents scientifiques de niveau recherche, publiés ou non, émanant des établissements d'enseignement et de recherche français ou étrangers, des laboratoires publics ou privés. 


\title{
Positron Annihilation for the Non-Destructive Assessment of the Early Stages of Damage
}

\author{
M.T. Hutchings, D.J. Buttle, R. Colbrook, W. Dalzell and C.B. Scruby \\ NDT Department, AEA Industrial Technology, 521 Harwell, Didcot, OX11 ORA, U.K.
}

\begin{abstract}
Positron annihilation $\gamma$-ray lineshape analysis is one of the few techniques which can provide an early warning of incipient materials degradation in metallic components. The National NDT Centre at AEA Technology Harwell has developed a portable NDT system, the Positron Annihilation Lineshape Analysis (PALA) System, which can be used to carry out measurements both in the laboratory and at external sites. The system utilises the narrowing of the annihilation gamma ray lineshape, which occurs if the annihilation event occurs near vacancies in the lattice of a metal, to give information on the early stages of damage. A brief description of the PALA system is given, and its use to measure plastic damage in a number of cases illustrated.
\end{abstract}

\section{INTRODUCTION}

A reliable means for monitoring incipient materials degradation, particularly where high-cycle fatigue is prevalent, is of importance to a range of industries. The Positron Annihilation technique assesses nondestructively the damage in metals and alloys caused by mechanical treatment or by irradiation. Its quantitative early indication of the onset of fatigue has important implications not only for plant maintenance, safety and reliability, but also for extending service life. Research at AEA Harwell into the development of positron annihilation has now been carried out for over a decade [1]. As a result of this work, a new portable NDE system, known as the PALA (Positron Annihilation Lineshape Analysis) System has been developed for use both in the laboratory and in the field. This paper briefly describes the PALA System, and gives examples of its use to measure plastic or fatigue damage in a number of cases.

\section{THE PALA TECHNIQUE}

The presence of vacancy defects, caused by incipient fatigue, creep, irradiation and certain other types of mechanical damage, disturbs the balance of positron annihilation statistics between annihilations with valence and conduction electrons [1,2]. Since the region of a vacancy defect with its absence of metal ions is negatively charged, it attracts and traps positrons. In this region annihilation is most likely to be with unlocalised conduction electrons which have a smaller momentum distribution than the valence electrons. Thus as the vacancy defect concentration is increased so also is the probability of the positron annihilating with conduction electrons rather than valence electrons. The width of the $\gamma$-ray energy 
spectral peak is therefore slightly reduced, as is the angular range between the coincidentally emitted $\gamma$ rays.

The PALA System has been optimised to measure this slight narrowing of the energy spectral peak, or 'lineshape', and hence to measure the increase in vacancy defect concentration. The change of the width of the $\gamma$-ray energy lineshape is measured by the lineshape parameter, $S$. This is defined as the ratio of the total counts in a narrow central region of the energy peak to the total counts in the whole peak. As the damage increases, the vacancy concentration increases, the energy spectral width decreases, and the ' $S$ ' parameter increases. Calibration curves can be generated relating the change in the $S$ parameter to the plastic strain using "tensile pull" samples, as described in section 4.1 below. The technique is sensitive to vacancy defects in the concentration range $10^{-7}$ to $10^{-4}$, and has a spatial resolution of $\sim 1 \mathrm{~mm}^{2}$. On average the positrons annihilate $\sim 0.5 \mathrm{~mm}$ beneath the surface so that normally no special surface preparation of the sample is necessary.

\section{THE PALA SYSTEM}

The AEA Technology PALA System is a high resolution, rapid inspection system which accurately measures the energy spectral peak of the annihilation $\gamma$-rays from the sample under test. The $\gamma$-ray detection system with associated laboratory peripherals is illustrated schematically in figure 1 , and is

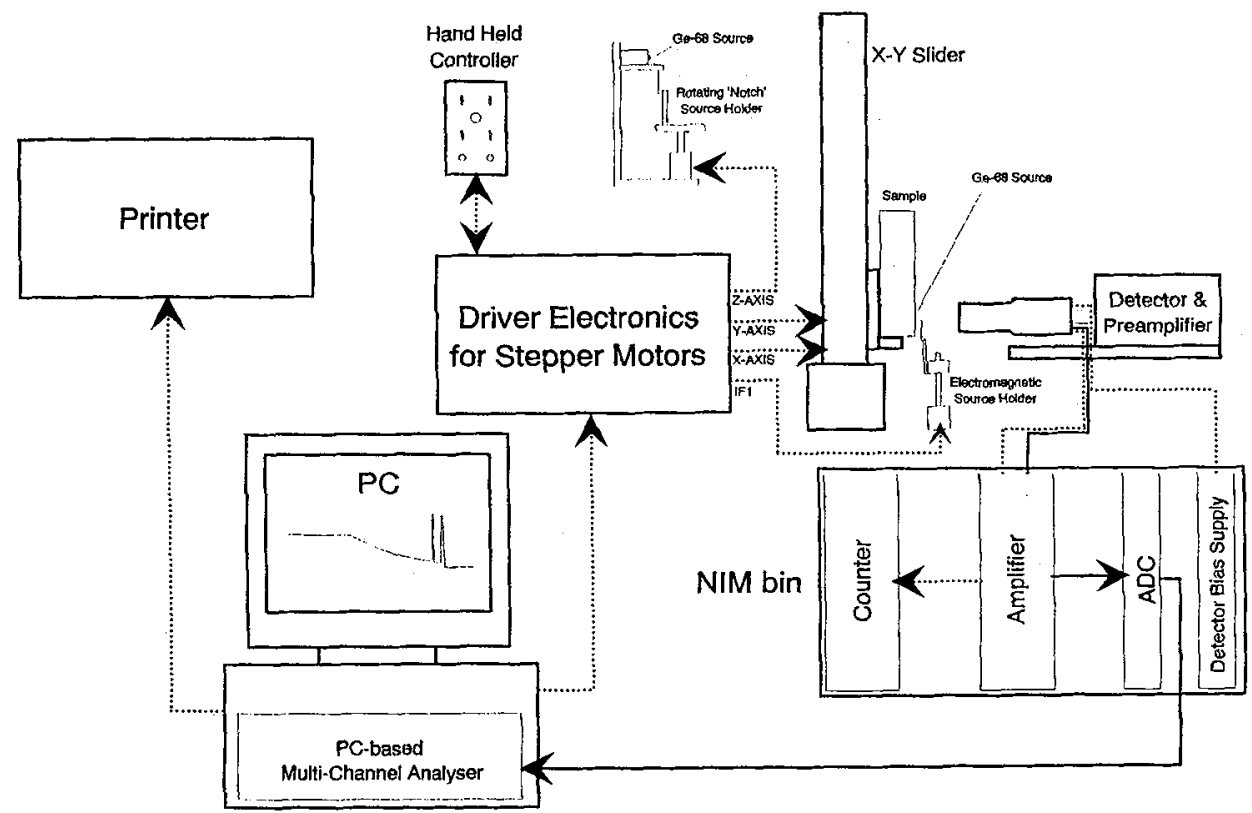

Figure 1 Schematic diagram of the PALA System, showing the path of the $\gamma$-ray spectrum signal as solid lines.

shown in the photograph, figure 2 . It consists of a portable, pure crystal, germanium $\gamma$-ray detector, cooled by liquid nitrogen which is held in a small dewar attached to the detector. The signal from the detector is sent via a special low noise preamplifier to the main amplifier of the system. This amplifies the signal, and applies corrections for ballistic deficit when using the short shaping times necessary for high count rates, and for pile up rejection. The signal is then digitised before being processed and stored in a PC-based multi-channel analyser. This results in an energy spectrum of the detected $\gamma$-rays being displayed in real time on the screen of the PC. 
The PALA System has been designed so as to maintain the highest energy resolution of the detected $\gamma$ ray energy spectral peaks whilst allowing a rapid incoming $\gamma$-ray count rate. Typically the resolution of a $\mathrm{Be}^{7}$ calibration peak at $478 \mathrm{keV}$, used for monitoring the System's preformance, is $\sim 1.35 \mathrm{keV}$ (FWHM) at an incoming count rate of $35,000 \mathrm{c} / \mathrm{s}$ when using a shaping time of $0.75 \mu \mathrm{s}$. Under these conditions the $\mathrm{S}$ parameter varies with count rate by less than $0.45 \%$ at rates up to $35,000 \mathrm{c} / \mathrm{s}$. This count rate enables

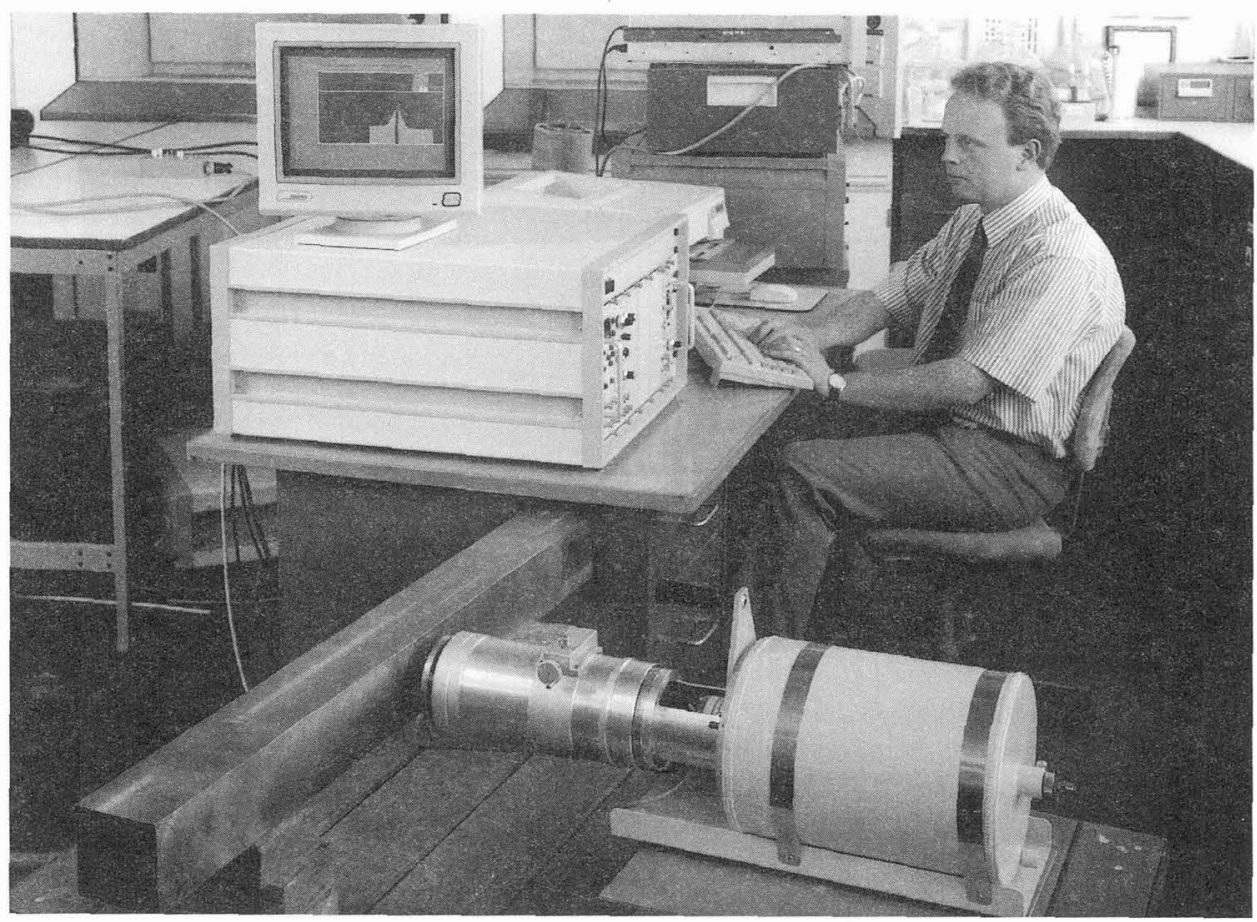

Figure 2 Photograph of the PALA System.

an accurate measurement to be made in only 3 to 5 minutes, corresponding to $\sim$ a few million counts in the annihilation peak. In the laboratory, the PALA System can be used in conjunction with computercontrolled sample and source manipulation systems, including an XY slider, with which to move a sample.

The positron source is a small $\mathrm{Ge}^{68}$ sample, of diameter $\sim 1 \mathrm{~mm}^{2}$, encapsulated in a specially designed aluminium holder to maintain good spatial resolution. This is placed against the sample using a sprung source holder. The activity of the source is $\sim 20 \mu \mathrm{Ci}$ in order to keep any radiation hazard to a minimum. About half the positrons annihilate in the sample and half in the aluminium holder, the latter giving a constant contribution to the lineshape. The electronic units are housed in a single crate and data collection and analysis performed by the PC. The data analysis software has been written to provide highly sensitive determination of the width of the $\gamma$-ray energy spectral peak.

In addition to laboratory use, the PALA System can be employed in the field using a specially designed sliding source holder attached to the detector, with one crate of electronics and a PC as shown in figure 2.

\section{EXAMPLES OF DAMAGE ASSESSMENT}

In this section we give examples of the use of the PALA System to assess plastic and fatigue damage in steel components. 


\subsection{Calibration}

The PALA technique can provide quantitative measurements providing a suitable calibration can be made on the same material under exactly the same conditions. An example of such a calibration is shown in figure 3 where the increase in S parameter with plastic strain is shown for a BS4360 mild steel bar which had been subjected to a uniaxial force. The plastic strain was measured with a strain gauge. The variation of $S$ can be modelled by a simple trapping model, and saturation occurs when all the positrons entering the sample are trapped at vacancy defects. The figure shows the range of sensitivity to the earlv stages of plastic damage in this material.

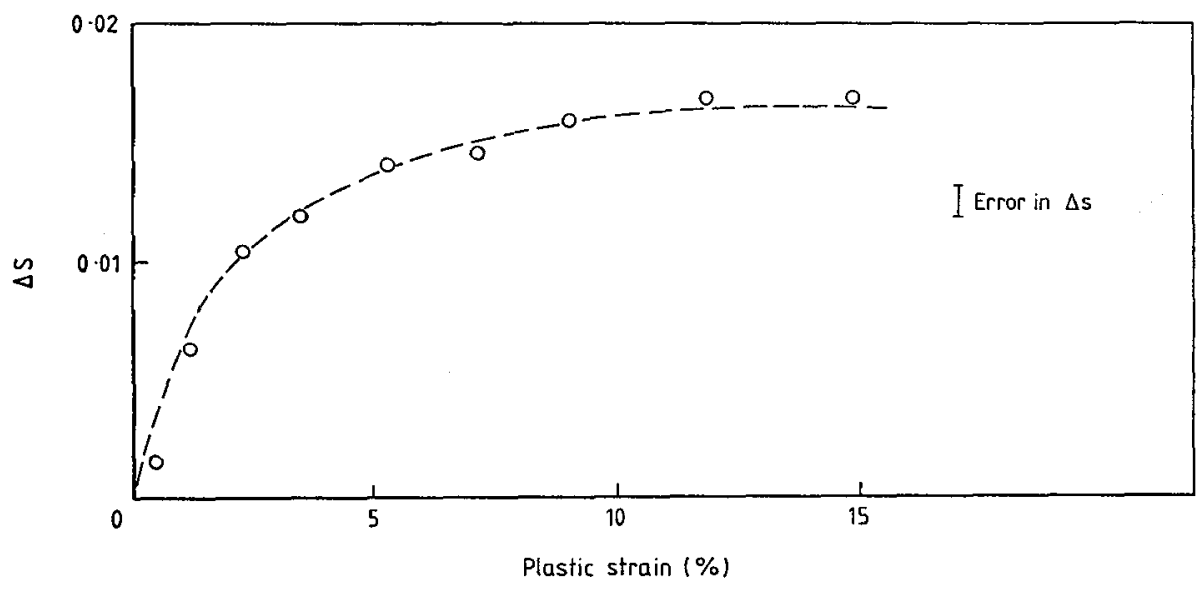

Figure 3 Calibration curve of increase in $\mathrm{s}$ parameter, which measures plastic damage, with plastic strain in a mild steel bar.

\subsection{A Plastically Bent Steel Bar}

The PALA technique is especially powerful when combined with other NDT techniques such as stress measurement. Figure 4 shows the variation of $S$ parameter with position on the side face of a plastically deformed BS4360 grade 43A mild steel bar, $1000 \times 100 \times 100 \mathrm{~mm}^{3}$ in dimensions. This had been subjected to 4-point bend with rollers symmetrically placed at 300 and $900 \mathrm{~mm}$ apart. The bent bar is shown under examination in figure 2. The PALA data shown as open circles are compared with measurement of the near-surface residual strain measured using the Stress-Induced Magnetic Anisotropy (SMA) technique [3]. The SMA technique provides a rapid measurement of the difference in the principal surface stress values. In this case measurements along the central line show that the principal stress axes lie along the symmetry axes of the bar and are consistent with near uniaxial stress. The SMA data thus give a good estimate of the value of the uniaxial stress. It is seen from the figure that there is high plastic damage in the outer regions of the bar, as expected, and that these are just the regions which have been subjected to the highest stress during bending, and in which the residual stress is reversed on releasing the four-point applied loading. Similar results have been presented on a smaller bar subjected to stronger bending, where the stress was measured down the centre of the bar using neutron diffraction [4].

\subsection{A Quality Tested Axle Housing}

In order to test steel tubular axle housing weldments, a sequence of 3-point bending loads are applied at each end. By using a combination of PALA and SMA techniques the stress history of the component can be ascertained, and the validity of the test established. An example of data acquired using these techniques is shown in figure 5 . These confirm that the component has been correctly quality tested for long life in service. Figure 5a shows an outline of the component, and the position (marked X) where measurements were made around the full $360^{\circ}$ of the circumference of the casing. The variation of 
PALA S parameter is shown in figure $5 \mathrm{~b}$, where it is seen that most plastic damage has occurred at $\sim 0^{\circ}$ and $\sim 180^{\circ}$, and the least $\sim 90^{\circ}$. These regions correlate well with those of highest residual stress, which is

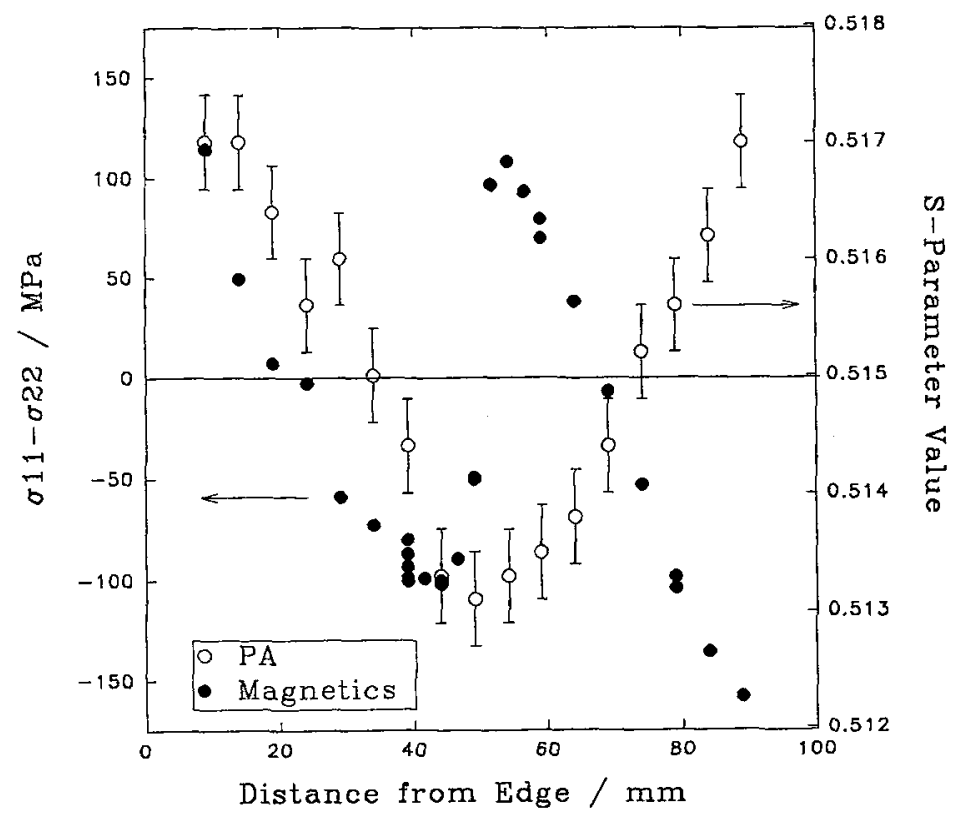

Figure 4 Comparison of plastic damage as measured by the $S$ parameter (o), and stress $(\bullet$ ) as measured by the magnetic technique SMA, across the side face of the plastically deformed bar.

shown in figure $5 \mathrm{c}$. The residual stress between $0^{\circ}$ and $180^{\circ}$ exhibits a similar variation to that in the plastically deformed bar shown in figure 4 , with compressive stress near $\sim 0^{\circ}$ and near $\sim 110^{\circ}$, and tensile stress near $\sim 55^{\circ}$ and $\sim 180^{\circ}$. The data indicate that during the tests net tensile stress, beyond yield, had been applied at $0^{\circ}$, and net compressive stress, beyond yield, at $180^{\circ}$, and then the tube allowed to equilibrate.

\subsection{A Fatigued Steel Bar}

As part of a larger investigation into fatigue cycling damage in BS4360 grade 50D steel, a bar, of dimensions $1000 \times 45 \times 45 \mathrm{~mm}^{3}$, has been progressively fatigued by 4-point tension-compression, with maximum force of $60 \mathrm{kN}$ applied using rollers symmetrically spaced by 300 and $900 \mathrm{~mm}$. Figure 6 shows the variation of $S$ parameter along the top surface of the bar after only initial low-load elastic cycling at $61 \%$ of yield, and after 300 cycles at $121 \%$ yield. The latter load is sufficient to result in nearsurface yield to a depth of $\sim 4 \mathrm{~mm}$ between the inner two bars. It is seen that initially there is little damage, but after only 300 cycles above yield, amounting to only a few percentage of fatigue life, there is near saturation of the PALA signal at positions between the inner rollers. However the damage falls off rapidly outside this inner region. As further fatiguing is carried out this saturation region moves out from the centre two roller positions.

\section{SUMMARY}

A brief description of the AEA Technology PALA System has been given, with examples which illustrate its successful use to detect plastic and fatigue damage. Although these measurements were all undertaken in the laboratory, the System is sufficiently portable that it can be used for work at outside sites. A more rugged system is being developed, and further work on applying it to study creep and radiation damage is being carried out. 


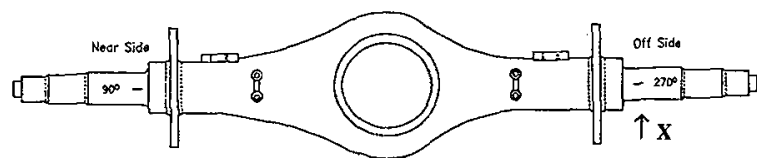

Viaw of Axlo Cosing from rast

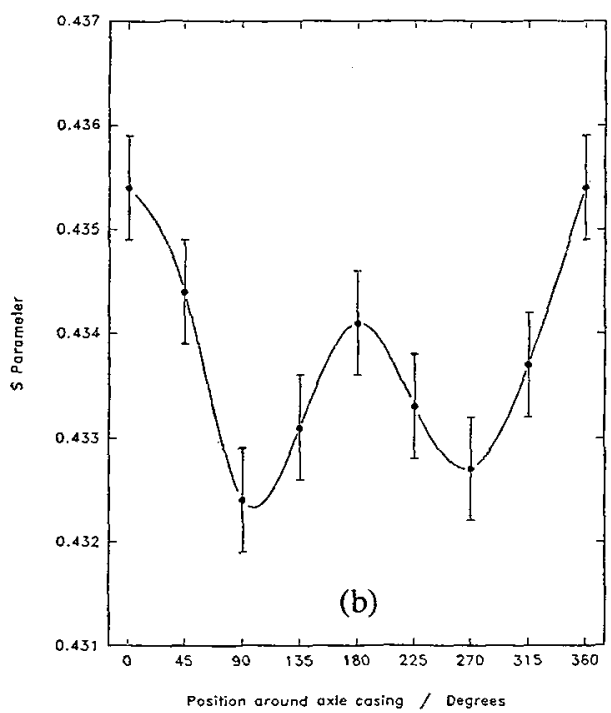

(a)

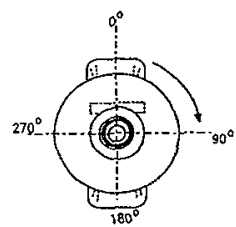

End on Viam of texle Cosing

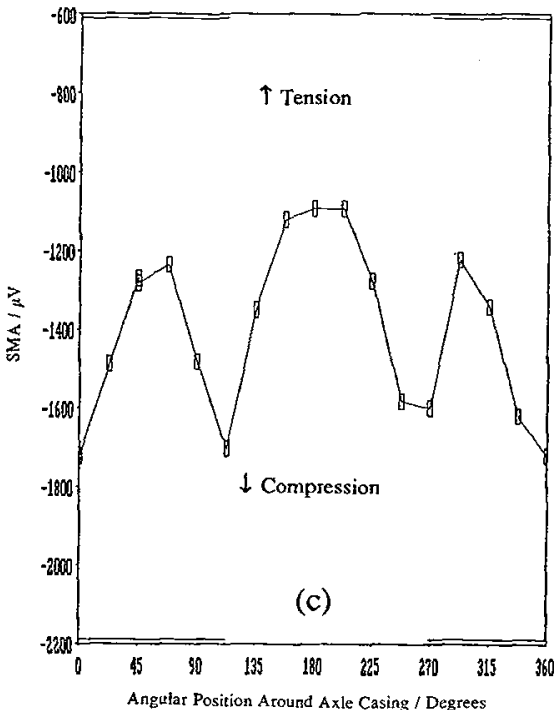

Figure 5 (a) An axle casing which had been subjected to quality testing which resulted in the expected variation of both plastic damage and residual stress.

(b) Plastic damage as measured by the PALA S parameter.

(c) Difference in principal stress values as measured by the SMA parameter.

There is an offset of $\sim-1500 \mu \mathrm{V}$ due to 'lift-off' effects from the curvature of the casing.

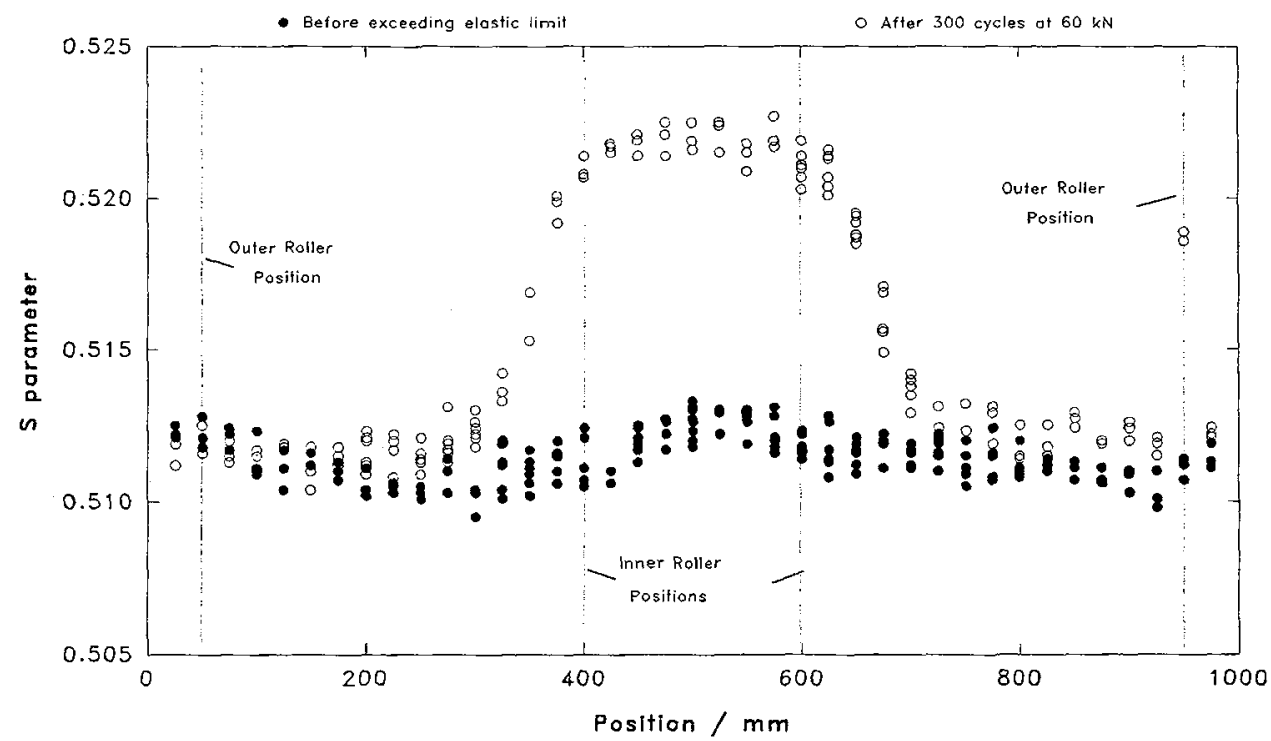

Figure $6(\bullet) \mathrm{S}$ parameter variation along the top face after only elastic fatigue loading. (o) $\mathrm{S}$ parameter variation after 300 fatigue cycles at $+/-60 \mathrm{kN}$ loading. 


\section{Acknowledgements}

Part of this work was undertaken with the support of the Corporate Research Programme of AEA Technology. The first PALA System has now been supplied to IHI Co. Ltd., Japan.

\section{References}

[1] Hughes A.E., Materials in Engineering 2 (1980) 34.

[2] Allen A.J., Coleman C.F., Conchie S.J. and Smith F.A., Mat. Res. Soc. Symp. Proc. 142 (1989) 131142.

[3] Buttle D.J. and Hutchings M.T., British J. Non-Destructive Testing 34 (1992) 175-182.

[4] Allen A.J., Coleman C.F., Conchie S.J., Hutchings M.T. and Smith F.A, "Non-Destructive Testing", Proc. 4th European Conference, London UK, 13-17 Sept. 1987, (Pergamon Press, Oxford, 1988) pp2193-2202. 